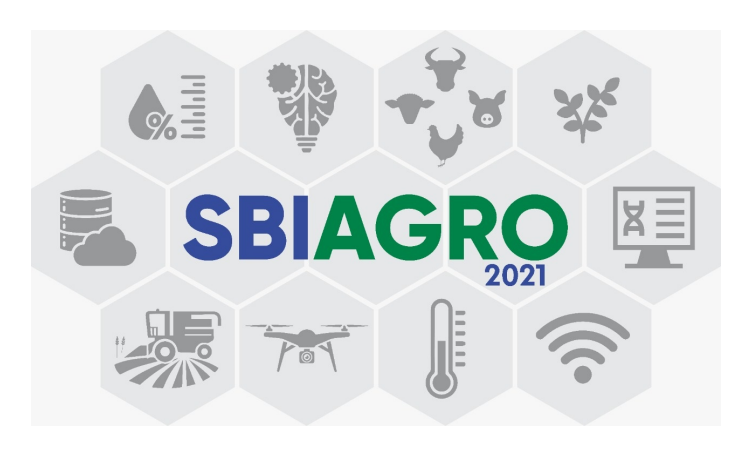

\title{
Perfil tecnológico e de automação das unidades armazenadoras de grãos do Estado do Paraná
}

\author{
Fernando Carvalho $^{1}$ and Luiz Antonio Rodrigues ${ }^{1}$ \\ ${ }^{1}$ Programa de Pós-Graduação em Ciência da Computação - PPGComp \\ Universidade Estadual do Oeste do Paraná - UNIOESTE \\ Cascavel - PR - Brasil \\ \{fernando.carvalho3, luiz.rodrigues\}@unioeste.br
}

\begin{abstract}
Paraná is one of the leading states in grain production in Brazil and has a static storage capacity of approximately 30 million tons. The storage conditions and its monitoring have a direct impact on the quality of the grains, which avoids losses and adds value to the product. The objective of this work was to investigate the level of adoption of information technologies and automation of storage units in Paraná, through an online data collection instrument applied to those responsible for units registered in SICARM. From the main results, it was observed that the level of automation is still low, especially in the Internet of Things (IoT) scenario, which indicates new market opportunities.
\end{abstract}

Resumo. O Paraná é um dos estados líderes na produção de grãos no Brasil e possui uma capacidade estática de armazenamento de aproximadamente 30 milhões de toneladas. As condições de armazenamento e o seu monitoramento têm impacto direto na qualidade dos grãos, o que evita perdas e agrega valor ao produto. O objetivo deste trabalho foi investigar o nível de adoção de tecnologias da informação e automação das unidades armazenadoras do Paraná, por meio de um instrumento de coleta de dados online aplicado aos responsáveis pelas unidades cadastradas no SICARM. A partir dos resultados, observa-se que o nível de automação ainda é baixo, especialmente no cenário de Internet das Coisas (IoT), o que indica novas oportunidades no mercado.

\section{Introdução}

A etapa de pós-colheita é constituída pelas fases do processo produtivo inerentes à conservação e o armazenamento dos alimentos, conforme Grolleaud (2002). A armazenagem está ligada ao conceito de abastecimento, que consiste em um conjunto de medidas necessárias para prover com regularidade, os alimentos que atendem às necessidades da 
população onde, no Brasil, destacam-se os estoques de determinados grãos cereais, como soja e milho, além do arroz, feijão, trigo, café, entre outros. Segundo Puzzi (2000), quaisquer mudanças na disponibilidade, qualidade ou preço destes produtos ou seus derivados, afetam a rotina socioeconômica de uma região ou país.

Para o armazenamento em perfeitas condições para posterior redistribuição e industrialização, os grãos são acondicionados nas Unidades Armazenadoras, também denominadas UAs, comumente chamados de silos e armazéns. O decreto 3.855/2001 institui como Unidades Armazenadoras as edificações, instalações e equipamentos destinados à guarda e conservação dos produtos agropecuários, seus derivados, subprodutos e resíduos de valor econômico [BRASIL 2001].

Em geral, as edificações mais utilizadas para o armazenamento de grãos são os silos metálicos, os armazéns graneleiros e os armazéns convencionais [Puzzi 2000, Paturca 2014]. Os silos são compartimentos estanques ou herméticos que, em virtude da compartimentação disponível, permitem o controle das características físico-biológicas dos grãos, que são armazenados separadamente conforme sua espécie e padrões agrícolas. Já os armazéns graneleiros, também denominados silos horizontais, são estruturas de concreto ou alvenaria, com cobertura metálica, e que separam o local em depósitos onde a massa de grãos é armazenada. Por ser uma estrutura para grandes volumes, há uma maior dificuldade de controle homogêneo e um maior risco de deterioração. Finalmente, os armazéns convencionais são estruturas de piso plano, comumente construídos em alvenaria, estruturas metálicas ou mistas, onde os produtos são estocados em sacaria, e devidamente empilhados e dispostos em blocos. Embora tenham baixo custo de instalação, a movimentação dos produtos é prejudicada.

Ressalta-se que após a colheita de gêneros alimentícios, não se pode adicionar qualidade aos produtos, sendo possível apenas a sua manutenção ou a minimização da deterioração natural de suas propriedades orgânicas. Destaca-se, pois, a importância do aprimoramento das tecnologias de suporte ao armazenamento de grãos, devido a necessidade da manutenção da qualidade dos mesmos durante todo o tempo em que são acondicionados, antes de serem transformados em diversos subprodutos industrializados.

A CONAB (Companhia Nacional de Abastecimento), é o órgão que controla e regula a atividade de armazenagem de grãos no Brasil, responsável também por manter o SICARM (Sistema de Cadastro Nacional de Unidades Armazenadoras) [SICARM 2021]. Este cadastro online contém dados, como o endereço e a localização geográfica dos armazéns, a razão social do proprietário e demais informações para contato, o tipo da estrutura edificada, e a sua capacidade estática de estocagem. No cadastro atual, atualizado em 23/08/2021, constam 2.469 UAs no Paraná, que somam aproximadamente 30 milhões de toneladas. Destas, 1.286 são Bateria de Silos (52,09\%), 528 Graneleiros (21,39\%), 457 Armazéns Convencionais (18,51\%), 169 Silos (6,84\%) e 29 outras estruturas $(1,17 \%)$.

Segundo relatório da Embrapa (Empresa Brasileira de Pesquisa Agropecuária) [EMBRAPA 2017], os sistemas baseados em Internet das Coisas (IoT) têm sido dedicados a monitorar ambientes das propriedades rurais, desde a análise de condições do solo até o monitoramento dos equipamentos e implementos utilizados em todas as fases da produção agrícola. No entanto, são poucas as iniciativas tecnológicas que apoiem o avanço da qualidade do armazenamento de grãos no Brasil. 
Assim, o objetivo deste trabalho foi investigar o nível de adoção de tecnologias da informação, incluindo a utilização de IoT, no ambiente de Unidades Armazenadoras no Estado do Paraná, bem como o nível de conhecimento técnico relacionado a automação destas estruturas por parte dos gestores e operadores de silos e armazéns.

O restante deste trabalho está organizado nas seguintes seções. A Seção 2 apresenta a metodologia de aplicação do instrumento de coleta de dados. A Seção 3 discute os resultados obtidos com base nas respostas de questionários completos. Por fim, a Seção 4 apresenta a conclusão e trabalhos futuros.

\section{Metodologia}

Para realizar a pesquisa, foi tomado por base o cadastro público do SICARM e todos os dados de disponíveis das pessoas jurídicas proprietárias de silos e armazéns com base no extrato de 2020, filtradas aquelas localizadas no Paraná. Para tanto, um questionário online foi elaborado e enviado para os 1.170 gestores ou responsáveis por armazéns no Paraná cadastrados no SICARM, considerando os e-mails únicos.

O formulário para captação das respostas foi desenvolvido no Google Forms ${ }^{1}$, contendo a caracterização da pesquisa, o TCLE (Termo de Consentimento Livre e Esclarecido), os dados de contato dos pesquisadores e as seções de perguntas. O envio e a gestão da sensibilização dos respondentes foi realizado com o Sendinblue ${ }^{2}$. Com o apoio desta ferramenta é possível verificar, além da quantidade de respostas completas e erros de entrega, quantos contatos realizaram a leitura do e-mail, abriram o link de resposta e optaram por não responder a pesquisa. Na primeira etapa foram enviados 1.323 convites. Destes, $1.051(79,4 \%)$ tiveram confirmação de entrega e o restante foi marcado com problemas na caixa de correio ou no cadastro. Dos entregues, $208(15,7 \%)$ foram abertos, mas apenas $46(3,48 \%)$ acessaram o questionário. Após cada rodada de sensibilização, as informações atualizadas foram utilizadas para o envio de lembretes mensais.

Uma vez que o avanço na captação de respostas via e-mail seguiu mais lento do que o esperado, por diversos motivos, desde a utilização de contas de e-mail que são pouco verificadas ou geridas por pessoas que não fazem parte do grupo de pesquisa, até mesmo pelo bloqueio do recebimento do contato por filtros anti-spam, foi iniciada uma fase de contatos por telefone. Os contatos telefônicos dos respondentes também foram obtidos no SICARM e, somente nos casos em que não havia tal informação, o número foi localizado em sites de busca pelo nome da empresa responsável pelo armazém. Nos meses de junho a outubro de 2020 foram contatadas 106 empresas para a sensibilização de resposta ao questionário, e convidadas a responder de imediato por telefone e registradas as respostas manualmente, ou solicitado o acesso posterior ao link do formulário. A partir deste processo foram obtidas 15 respostas.

No total, somadas as iniciativas de contato por e-mail e telefone, foram obtidas 45 respostas completas, devidamente registradas no formulário criado para a captação dos dados, seja por iniciativa dos próprios respondentes, seja por lançamento manual pelo responsável da pesquisa. Isto equivale a 4,28\% dos e-mails válidos.

\footnotetext{
${ }^{1}$ Google Forms: https:// forms.google.com

${ }^{2}$ Sendinblue: https://pt. sendinblue.com
} 


\section{Resultados e discussão}

Os resultados da pesquisa foram obtidos por meio de um questionário constituído por 34 perguntas objetivas divididas nas seções apresentadas a seguir.

\subsection{Seção I - Perfil do respondente e ambiente de armazenamento da empresa}

Na primeira seção do instrumento são abordadas as questões de formação e atuação do respondente, bem como sobre seu conhecimento relativo ao ambiente de armazenagem da empresa. Inclui ainda o perfil das UAs sob responsabilidade da empresa.

Em relação ao nível de formação escolar, a maioria possui ensino superior $(53,3 \%)$ ou especialização (40\%). Ensino médio e nível técnico em agropecuária totalizam 4,4\%. Mestrado ou doutorado, 2,2\%. O nível hierárquico dos respondentes é majoritariamente de Supervisores ou Coordenadores (46,7\%), seguido de Gerente ou Diretor (40\%) e Técnico/Analista (13,3\%). Quanto ao tempo de atuação na empresa, a maior parte atua há mais de 10 anos (48,9\%). A atuação de 1 a 5 anos representa $28,9 \%$ e outros $20 \%$ atuam entre 6 e 10 anos. Apenas um respondente trabalha há menos de um ano na função, que representam $2,2 \%$ do total.

A capacidade de armazenamento das unidades sob gerência dos respondentes está registrada na Tabela 1. A maioria das empresas (cerca de 64\%) possuem capacidade de até 50 mil toneladas. O restante, cerca de $35 \%$, possuem capacidade de armazenamento superior a 50 mil, sendo em 12 delas, superior a 100 mil.

Tabela 1. Capacidade aproximada de armazenamento de grãos da empresa.

\begin{tabular}{|l|rr|}
\hline Capacidade de Armazenamento & \multicolumn{2}{|c|}{ Resultado } \\
\hline De 5 mil até 10 mil t. & 11 & $(24,4 \%)$ \\
\hline De 10 mil até 50 mil t. & 18 & $(40,0 \%)$ \\
\hline De 50 mil até 100 mil t. & 4 & $(8,9 \%)$ \\
\hline Acima de 100 mil t. & 12 & $(26,7 \%)$ \\
\hline Total & 45 & $(100.0 \%)$ \\
\hline
\end{tabular}

O gráfico da Figura 1(a) representa os tipos de armazéns agrupados individualmente conforme as respostas. Verifica-se que o tipo Bateria de Silos é o mais utilizado nas empresas pesquisadas, correspondendo a 88,9\%. O segundo tipo é o Graneleiro, com $60 \%$, e o tipo Silo individual foi indicado por $20 \%$. Já a categoria Convencional, onde os grãos não são estocados a granel, totaliza $42,2 \%$ das respostas. Por se tratar de uma questão de múltipla escolha, a soma ultrapassa os $100 \%$.

Verifica-se pela Figura 1(b) que as empresas consultadas armazenam majoritariamente soja e milho, tendo a soja 88,9\% de indicações, e o milho com 82,2\%. Observa-se ainda uma considerável parcela de armazenamento de trigo $(62,2 \%)$, assim como algumas ocorrências de armazenadores de feijão, aveia e arroz.

Na Tabela 2, que contém os dados da idade média das edificações de armazenamento, é possível observar que $80 \%$ das mesmas possuem mais de 10 anos, sendo que neste arranjo, 23 informaram idade entre 10 e 20 anos, e 13 informaram que as UAs possuem mais de 20 anos. Desta forma, $20 \%$ dos respondentes indicaram que as instalações possuem menos de 10 anos, sendo que apenas 2 destas foram construídas há menos de 5 anos. 


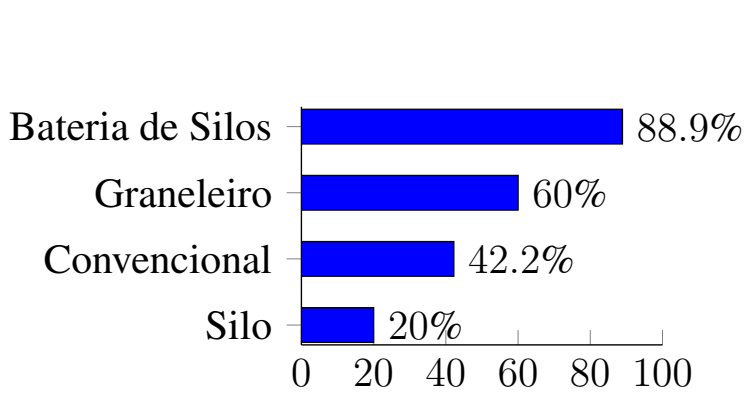

(a) Tipos de armazéns

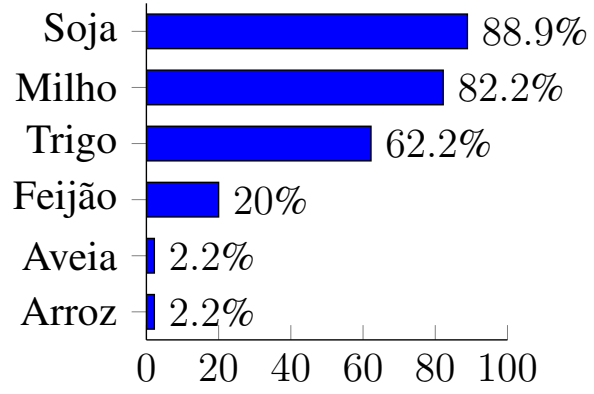

(b) Grãos armazenados

Figura 1. Resultados agrupados para a) tipos de armazéns instalados e b) tipos de grãos armazenados nas empresas consultadas.

Tabela 2. Idade estimada das unidades armazenadoras de grãos.

\begin{tabular}{|l|rr|}
\hline Idade Estimada das UAs & \multicolumn{2}{|c|}{ Resultado } \\
\hline Menos de 5 anos & 2 & $(4,4 \%)$ \\
\hline Entre 5 e 10 anos & 7 & $(15,6 \%)$ \\
\hline Entre 10 e 20 anos & 23 & $(51,1 \%)$ \\
\hline Mais de 20 anos & 13 & $(28,9 \%)$ \\
\hline Total & 45 & $(100,0 \%)$ \\
\hline
\end{tabular}

Para descobrir também o entendimento dos operadores em relação aos conceitos de "Automação de Silos", 88,9\% consideraram-se parcialmente ou já familiarizados com o assunto, enquanto 86,7\% indicaram conhecer o tema "Internet das Coisas", ao menos em partes, como pode ser visto na (Tabela 3 ).

\section{Tabela 3. Familiaridade dos respondentes com os conceitos de "Automação de Silos" e "Internet das Coisas".}

\begin{tabular}{|l|c|c|r|}
\hline \multicolumn{1}{|c|}{ Questão } & Não & Sim & Parcialmente \\
\hline $\begin{array}{l}\text { Você está familiarizado com o conceito de } \\
\text { Automação em Silos e Armazéns de grãos? }\end{array}$ & $5(11,1 \%)$ & $28(62,2 \%)$ & $12(26,7 \%)$ \\
\hline $\begin{array}{l}\text { Você está familiarizado com o conceito de } \\
\text { IoT ou "Internet das Coisas"? }\end{array}$ & $6(13,3 \%)$ & $18(40,0 \%)$ & $21(46,7 \%)$ \\
\hline
\end{tabular}

\subsection{Seção II - Uso de tecnologias de automação}

Na segunda seção de perguntas, o questionário aborda sobre o uso de tecnologias de informação nos ambientes de armazenagem das empresas. As questões foram organizadas em uma única tabela, na qual as linhas separam diferentes tecnologias como sensores digitais, sistemas MES/SCADA ou CAD/CAM/CAE, simulações virtuais, análise de Big Data e utilização de Computação em Nuvem, e as colunas indicam o nível de adoção ou intenção de utilização para cada uma delas.

De acordo com os dados contidos na Tabela 4, 84,4\% das empresas pesquisadas utilizam sensores sem automação. A indicação de não utilização de sensores $(15,6 \%)$, pode ser justificada por equívocos no preenchimento, pelo desconhecimento do respondente quanto a existência de sensores na UA, ou ainda por se tratar de armazém do tipo Convencional que não dispõe deste recurso. Já a utilização de sensores baseados em 
terminais é indicada por $55,6 \%$ dos pesquisados. Com relação as demais tecnologias, destaca-se a baixa adesão às tecnologias mais recentes, como a simulação e análise através de modelos virtuais indicada por 6,7\%, o emprego de processamento de grandes bases de dados (Big Data) e de dispositivos IoT, apontados por 8,9\% dos pesquisados. Ressaltase, porém, a intenção dos pesquisados em aderir a estas novas tecnologias nos próximos anos, tendo indicado a possibilidade de adotar, em até 5 anos ou mais, a computação em nuvem (20\%), Big Data (26,7\%) e IoT (33,3\%).

Tabela 4. Utilização de tecnologias de automação, monitoramento e informação nas unidades armazenadoras de grãos.

\begin{tabular}{|l|c|c|c|c|}
\hline \multicolumn{1}{|c|}{ Tecnologia } & Utiliza & Não Utiliza & $\begin{array}{c}\text { Pretende } \\
\text { adotar em } \\
\text { Até 5 anos }\end{array}$ & $\begin{array}{c}\text { Pretende } \\
\text { adotar em } \\
\text { anos ou mais }\end{array}$ \\
\hline Sensores sem automação & $38(84,4 \%)$ & $7(15,6 \%)$ & 0 & 0 \\
\hline $\begin{array}{l}\text { Automação digital s/ sensores } \\
\text { baseada em terminais }\end{array}$ & $25(55,6 \%)$ & $17(37,8 \%)$ & $3(6,7 \%)$ & 0 \\
\hline $\begin{array}{l}\text { Automação digital c/ sensores } \\
\text { p/ controle de processos } \\
\text { ou ident. de produtos }\end{array}$ & $12(26,7 \%)$ & $21(46,7 \%)$ & $8(17,8 \%)$ & $4(8,9 \%)$ \\
\hline $\begin{array}{l}\text { Monitoramento e controle } \\
\text { remoto de produção com } \\
\text { sist. MES/SCADA }\end{array}$ & $11(24,4 \%)$ & $38(84,4 \%)$ & $3(6,7 \%)$ & $3(6,7 \%)$ \\
\hline $\begin{array}{l}\text { Sistemas Integrados de Eng. } \\
\text { (CAD/CAM/CAE/PDM) }\end{array}$ & $12(26,7 \%)$ & $27(60,0 \%)$ & $4(8,9 \%)$ & $2(4,4 \%)$ \\
\hline $\begin{array}{l}\text { Simulação/análise } \\
\text { de modelos virtuais }\end{array}$ & $3(6,7 \%)$ & $34(75,6 \%)$ & $6(13,3 \%)$ & $2(4,4 \%)$ \\
\hline $\begin{array}{l}\text { Coleta, proc., análise de gdes. } \\
\text { qtds. de dados (Big Data) }\end{array}$ & $4(8,9 \%)$ & $29(64,4 \%)$ & $7(15,6 \%)$ & $5(11,1 \%)$ \\
\hline $\begin{array}{l}\text { Utilização de serviços em } \\
\text { nuvem relacionados à } \\
\text { operação (Cloud Computing) }\end{array}$ & $12(26,7 \%)$ & $24(53,3 \%)$ & $5(11,1 \%)$ & $4(8,9 \%)$ \\
\hline $\begin{array}{l}\text { Incorporação de serviços } \\
\text { digitais aos equipamentos } \\
\text { da operação (IoT) }\end{array}$ & $4(8,9 \%)$ & $26(57,8 \%)$ & $9(20,0 \%)$ & $6(13,3 \%)$ \\
\hline
\end{tabular}

\subsection{Seção III - Desafios na adoção de novas tecnologias}

O objetivo desta seção era determinar quais são os itens possivelmente impeditivos, na visão dos entrevistados, relacionados aos custos de implantação e manutenção voltados a adoção de novas tecnologias no processo de armazenagem de grãos em suas unidades.

Verifica-se na Tabela 5 que $60 \%$ das empresas consideraram irrelevante ou pouco impeditiva a falta da padronização de protocolos de comunicação industrial que possam ser utilizados na operação de armazenamento de grãos. Todavia, 82,2\% indicaram ser moderado ou altamente impeditivo o custo para adoção destas tecnologias e sistemas.

Em relação às despesas de manutenção, $71,1 \%$ dos respondentes informaram que este fator é impeditivo em um nível moderado ou alto, assim como outros 71,1\% apontaram também a falta de profissionais capacitados na operação dos sistemas. A respeito dos riscos ou a incerteza sobre o Retorno do Investimento (ROI) em novas tecnologias, houve um equilíbrio nas respostas, onde 53,3\% consideram como desafio pouco impeditivo ou irrelevante, enquanto $47,7 \%$ julgam ser moderadamente ou altamente impeditivo. 
Tabela 5. Nível dos desafios enfrentados pelas empresas para a adoção de novas tecnologias ou sistemas nas unidades de armazenamento.

\begin{tabular}{|l|c|c|c|c|}
\hline \multicolumn{1}{|c|}{$\begin{array}{c}\text { Desafios para } \\
\text { adoção de tecnologias }\end{array}$} & Irrelevante & $\begin{array}{c}\text { Pouco } \\
\text { Impeditivo }\end{array}$ & $\begin{array}{c}\text { Moderadamente } \\
\text { Impeditivo }\end{array}$ & $\begin{array}{c}\text { Altamente } \\
\text { Impeditivo }\end{array}$ \\
\hline $\begin{array}{l}\text { Falta de padronização nos } \\
\text { protocolos de comunicação industrial }\end{array}$ & $9(20,0 \%)$ & $18(40,0 \%)$ & $14(31,1 \%)$ & $4(8,9 \%)$ \\
\hline $\begin{array}{l}\text { Custo para adoção das } \\
\text { tecnologias/sistemas }\end{array}$ & $2(4,4 \%)$ & $6(13,3 \%)$ & $18(40,0 \%)$ & $19(42,2 \%)$ \\
\hline $\begin{array}{l}\text { Despesas de manutenção das } \\
\text { tecnologias/sistemas }\end{array}$ & $1(2,2 \%)$ & $12(26,7 \%)$ & $13(28,9 \%)$ & $19(42,2 \%)$ \\
\hline $\begin{array}{l}\text { Riscos ou incerteza sobre o } \\
\text { ROI nas tecnologias/sistemas }\end{array}$ & $5(11,1 \%)$ & $19(42,2 \%)$ & $10(22,2 \%)$ & $11(24,4 \%)$ \\
\hline Falta de recursos financeiros & $3(6,7 \%)$ & $17(37,8 \%)$ & $17(37,8 \%)$ & $8(17,8 \%)$ \\
\hline $\begin{array}{l}\text { Falta de profissionais capacitados } \\
\text { na operação das tecnolog/sist. }\end{array}$ & $4(8,9 \%)$ & $9(20,0 \%)$ & $18(40,0 \%)$ & $14(31,1 \%)$ \\
\hline Falta de capacidade técnica em TI & $7(15,6 \%)$ & $18(40,0 \%)$ & $12(26,7 \%)$ & $8(17,8 \%)$ \\
\hline Risco para operação & $5(11,1 \%)$ & $18(40,0 \%)$ & $17(37,8 \%)$ & $5(11,1 \%)$ \\
\hline $\begin{array}{l}\text { Risco para a segurança dos } \\
\text { dados/informação }\end{array}$ & $6(13,3 \%)$ & $23(51,1 \%)$ & $6(13,3 \%)$ & $10(22,2 \%)$ \\
\hline
\end{tabular}

A falta de recursos financeiros para a adoção de novas tecnologias é considerada um desafio alto ou moderado para 55,6\%. Já no aspecto técnico, $71,1 \%$ apontaram a falta de capacidade técnica na operação como impeditivo, ao passo que $44,4 \%$ julgam a falta de capacidade técnica na equipe de TI. Com relação aos riscos, 51,1\% consideram irrelevante ou pouco impeditivo, o risco para a operação de armazenagem, enquanto $64,4 \%$ subestimam o risco à segurança da informação.

\subsection{Seção IV - Resultados esperados quando da adoção de novas tecnologias}

$\mathrm{Na}$ última seção, as perguntas são relacionadas aos resultados pretendidos com a adoção de novas tecnologias em UAs, com foco no aumento das receitas pela manutenção da qualidade dos produtos armazenados, a manutenção do mercado atual e a entrada em novos mercados, a melhoria na operação ou processo de armazenagem, e a inovação.

Tabela 6. Resultados pretendidos no caso de adoção de novas tecnologias ou sistemas nas Unidades de Armazenamento.

\begin{tabular}{|l|c|c|c|c|}
\hline \multicolumn{1}{|c|}{ Resultados pretendidos } & $\begin{array}{c}\text { Nenhum } \\
\text { Resultado }\end{array}$ & $\begin{array}{c}\text { Baixos } \\
\text { Resultados }\end{array}$ & $\begin{array}{c}\text { Alguns } \\
\text { Resultados }\end{array}$ & $\begin{array}{c}\text { Altos } \\
\text { Resultados }\end{array}$ \\
\hline $\begin{array}{l}\text { Aumento das receitas pela } \\
\text { qualidade do produto }\end{array}$ & 0 & $2(4,4 \%)$ & $19(42,2 \%)$ & $24(53,3 \%)$ \\
\hline Entrada em novos mercados & $6(13,3 \%)$ & $10(22,2 \%)$ & $14(31,1 \%)$ & $15(33,3 \%)$ \\
\hline Manutenção do mercado atual & $1(2,2 \%)$ & $10(22,2 \%)$ & $19(42,2 \%)$ & $15(33,3 \%)$ \\
\hline Melhoria na operação ou processo & 0 & $1(2,2 \%)$ & $14(31,1 \%)$ & $30(66,7 \%)$ \\
\hline Melhoria por inovação & $1(2,2 \%)$ & $5(11,1 \%)$ & $14(31,1 \%)$ & $25(55,6 \%)$ \\
\hline
\end{tabular}

A melhoria na operação ou no processo, foi o resultado de mais alta expectativa indicado pela maioria dos respondentes $(98,8 \%)$, seguido pelo aumento nas receitas pela qualidade do produto, com 95,6\%. Na sequência foram apontados ainda a melhoria por inovação $(86,7 \%)$ e a manutenção dos mercados atuais $(75,5 \%)$. Já a entrada em novos mercados foi o resultado de menor expectativa $(64,4 \%)$. 


\subsection{Discussões}

Verifica-se que a grande maioria dos profissionais responsáveis pelas UAs do Paraná possuem ensino superior ou pós-graduação em algum nível, lato sensu ou stricto sensu, e que em geral, atuam há pelo menos 5 anos neste setor.

Quanto ao perfil das UAs, observa-se que os tipos Bateria de Silos e Graneleiros predominam nas empresas, assim como destaca-se a idade avançada das estruturas, onde a maioria pesquisada encontra-se nas faixas acima de 10 anos ou mais. Denota-se também que os grãos armazenados por estas estruturas são, em sua maioria, soja e milho.

Nota-se também, que há familiaridade dos respondentes com os conceitos de automação de silos, tendo aproximadamente $88 \%$ indicado conhecê-los parcial ou totalmente. Além disso, cerca de $86 \%$ afirmaram entender a definição de Internet das Coisas.

Ainda com relação às aplicações de tecnologias na operação de silos e armazéns, se observa a predominância no emprego de sensores sem automação ou até mesmo de sensores digitais automatizados. No entanto, o uso de tecnologias mais recentes na automação e monitoramento das estruturas e dos produtos estocados, como a Computação em Nuvem e a Internet das Coisas, são pouco frequentes na rotina dos entrevistados. Este cenário é semelhante ao discutido por [Puzzi 2000] acerca do monitoramento em UAs que utilizam sensores termopares e pela observação de dezenas de armazéns que ainda utilizam este sistema de controle.

Finalmente, os principais desafios indicados para a utilização de novas tecnologias na operação de UAs, foram os custos das tecnologias e sistemas para este propósito, tanto para a implantação quanto para a manutenção. Em contrapartida, esperam o aumento das receitas pela maior qualidade do produto, e a melhoria no processo operacional, quando da aplicação destas tecnologias.

\section{Conclusão}

O objetivo desta pesquisa foi verificar qual é o nível de automação das UAs do Estado do Paraná, incluindo o perfil dos gestores e profissionais que as operam, as suas expectativas em relação a adoção de novas tecnologias que permitam o aprimoramento da atividade, bem como quais os desafios mais relevantes para adoção destas.

Para tanto, um questionário online foi inicialmente enviado aos e-mails dos gestores cadastrados no banco de dados do SICARM. Posteriormente, considerando o grande número de falhas de entregas e o baixo retorno de respostas, foram também realizadas algumas ligações telefônicas.

Embora considerável parcela dos respondentes afirme conhecer os conceitos de automação de silos $(62,2 \%)$ e Internet das Coisas (40\%), verifica-se pelos resultados que há uma baixa utilização pelos sistemas destas categorias nas UAs, especialmente para a coleta de informações ambientais, tão importantes para a manutenção da qualidade dos grãos. Embora o custo seja considerado impeditivo, há interesse na adoção de novas tecnologias em até 5 anos ou mais, mas ainda pouco significativa. 


\section{Referências}

BRASIL (2001). Decreto no 3.855, de 3 de julho de 2001. Acesso em: 22 jul. 2020.

EMBRAPA (2017). Internet das coisas (iot): inovação para o agronegócio. EMBRAPA Secretaria de Inteligência e Macroestratégia: Diálogos Estratégicos.

Grolleaud, M. (2002). Post-harvest losses: discovering the full story. Overview of the phenomenon of losses during the Post-harvest. Acesso em: 10 nov. 2019.

Paturca, E. Y. (2014). Caracterização das estruturas de armazenagem de grãos: um estudo de caso no Mato Grosso. PhD thesis, Universidade de São Paulo.

Puzzi, D. (2000). Abastecimento e armazenagem de grãos. Instituto Campineiro de Ensino Agricola.

SICARM (2021). Sistema de Cadastro Nacional de Unidades Armazenadoras. Acesso em: 27 abr. 2021. 